\title{
Laparoscopic resection of a large clinically silent paraganglioma at the organ of Zuckerkandl: a rare case report and review of the literature
}

\author{
Xiang Ren ${ }^{1}$, Jiwen Shang ${ }^{1,2^{*}} \mathbb{D}$, Ruimin Ren ${ }^{2}$, Huajun Zhang $^{2}$ and Xue Yao ${ }^{2}$
}

\begin{abstract}
Background: Large paraganglioma of the Zuckerkandl organ (POZ) is extremely rare. The patient can occasionally be paucisymptomatic, further obscuring the diagnosis and carrying high mortality. Recommended treatment for large paraganglioma $(\mathrm{PGL}$ ) is open surgical removal. We report a case of successful laparoscopic resection of a large POZ with normal blood pressure in a 45-year-old man.

Case presentation: A 45-year-old man was hospitalized because of hyperglycemia. Computed tomography of the abdomen and the serum and urinary catecholamine levels confirmed the diagnosis of large POZ. But his blood pressure was normal and he underwent laparoscopic tumor excision successfully. During 6 months follow-up after laparoscopy, serum and urinary catecholamines were normal but glycaemia remained high level. DNA analysis of the succinate dehydrogenase complex subunits B (SDHB) and SDHD revealed no mutation.

Conclusions: $\mathrm{POZ}$ is an unusual mass and preoperative diagnosis can be difficult in clinically silent cases. PGL cannot be excluded in patients with normal blood pressure. Even a large POZ can be excised laparoscopically by following proper techniques.
\end{abstract}

Keywords: Paraganglioma, Large, Silent, Organ of zuckerkandl, Laparoscopy, Genetic testing

\section{Background}

PGLs are catecholamine-producing tumors that may occur anywhere along the sympathetic paraganglionic chain [1]. The treatment of PGL including its diagnosis is difficult, especially when some patients lack typical clinical signs and symptoms (headache, palpitations, sweating, or hypertension) which are due to the direct actions of secreted catecholamines. About 53\% of PGLs occur in the organs of Zuckerkandl [2], which are a collection of paraganglia located anterolaterally to the distal abdominal aorta between the origin of the inferior mesenteric

\footnotetext{
*Correspondence: sjw139@126.com

1 Graduate School, Shanxi Medical University, Taiyuan 030000, China

Full list of author information is available at the end of the article
}

artery or renal artery and the aortic bifurcation. The majority of POZs are non-functional [3], so misdiagnosis and missed diagnosis are common. Traditional treatment for large POZ was open surgical resection, and only a few cases of laparoscopic approach to this pathology have been reported (Table 1). We report a case of successful laparoscopic resection of a large POZ with normal blood pressure in a 45-year-old man and review the related literature on POZ.

\section{Case presentation}

A 45-year-old man with a half-year history of hyperglycemia presented to endocrinology. The patient denied attacks of headache, hypertension, palpitation and sweating. He was kept for observation with 24-h 
electrocardiography (ECG) and blood pressure monitoring which was normal. His glycaemia returned to normal level under the action of insulin. Haematological and biochemical investigations were normal except for elevated serum and urinary catecholamines (Table 2).
Abdominal-pelvic CT scan with contrast injection had revealed a $7.2 \times 6.5 \mathrm{~cm}$ inhomogeneous, right para-aortic mass located at the level of the inferior mesenteric artery (Fig. 1). Both the adrenals were normal. With these findings, a diagnosis of $\mathrm{POZ}$ was reached. However, due to

Table 1 Cases of laparoscopic resection of a large POZ reported in the literature

\begin{tabular}{lllllllll}
\hline Case & References & Misdiagnosis & Age (years) & Size $(\mathbf{c m})$ & Time $(\mathbf{m i n})$ & Blood loss $(\mathbf{m L})$ & $\begin{array}{l}\text { Genetic } \\
\text { screening }\end{array}$ & \begin{tabular}{l} 
Gene mutation \\
\hline 1
\end{tabular} \\
& Kravarusic et al. [4] & No & 14 & 6 & NA & NA & Yes & SDHB \\
2 & Thapar et al. [5] & No & 20 & $6.5 \times 5$ & NA & 300 & No & - \\
3 & Cozzupoli et al. [6] & NA & 20 & 10 & NA & NA & NA & NA \\
4 & Salgaonkar et al. [3] & No & 22 & $8 \times 7$ & 125 & 40 & No & - \\
5 & Joshi et al. [7] & Yes & 28 & $7.5 \times 6.6 \times 7.5$ & NA & NA & No & - \\
Present & & Yes & 45 & $7.2 \times 6.5$ & 120 & 50 & Yes & No \\
\hline
\end{tabular}

NA not available

Table 2 Blood and urinary analysis

\begin{tabular}{|c|c|c|c|}
\hline & Upon presentation & 6 months follow-up & Reference values \\
\hline Blood pressure (max) & 118/76 mmHg & $115 / 75 \mathrm{mmHg}$ & $100-120 / 60-80 \mathrm{mmHg}$ \\
\hline Fasting blood-glucose (max) & $7.5 \mathrm{mmol} / \mathrm{L}$ & $7.4 \mathrm{mmol} / \mathrm{L}$ & $3.9-6.1 \mathrm{mmol} / \mathrm{L}$ \\
\hline \multicolumn{4}{|l|}{ Blood } \\
\hline Adrenaline & $1050 \mathrm{pg} / \mathrm{mL}$ & $39.7 \mathrm{pg} / \mathrm{mL}$ & $0-100 \mathrm{pg} / \mathrm{mL}$ \\
\hline Noradrenaline & $650 \mathrm{pg} / \mathrm{mL}$ & $168.0 \mathrm{pg} / \mathrm{mL}$ & $0-600 \mathrm{pg} / \mathrm{mL}$ \\
\hline Dopamine & $102 \mathrm{pg} / \mathrm{mL}$ & $59.17 \mathrm{pg} / \mathrm{mL}$ & $0-100 \mathrm{pg} / \mathrm{mL}$ \\
\hline \multicolumn{4}{|l|}{ Urine } \\
\hline Metanephrines $24 \mathrm{~h}$ & $2120 \mathrm{mg} / 24 \mathrm{~h}$ & $190 \mathrm{mg} / 24 \mathrm{~h}$ & $64-350 \mathrm{mg} / 24 \mathrm{~h}$ \\
\hline Normetanephrines $24 \mathrm{~h}$ & $4252 \mathrm{mg} / 24 \mathrm{~h}$ & $260 \mathrm{mg} / 24 \mathrm{~h}$ & $120-490 \mathrm{mg} / 24 \mathrm{~h}$ \\
\hline Vanillylmandelic acid $24 \mathrm{~h}$ & $35 \mathrm{mg} / 24 \mathrm{~h}$ & $6.0 \mathrm{mg} / 24 \mathrm{~h}$ & $2.0-7.1 \mathrm{mg} / 24 \mathrm{~h}$ \\
\hline
\end{tabular}
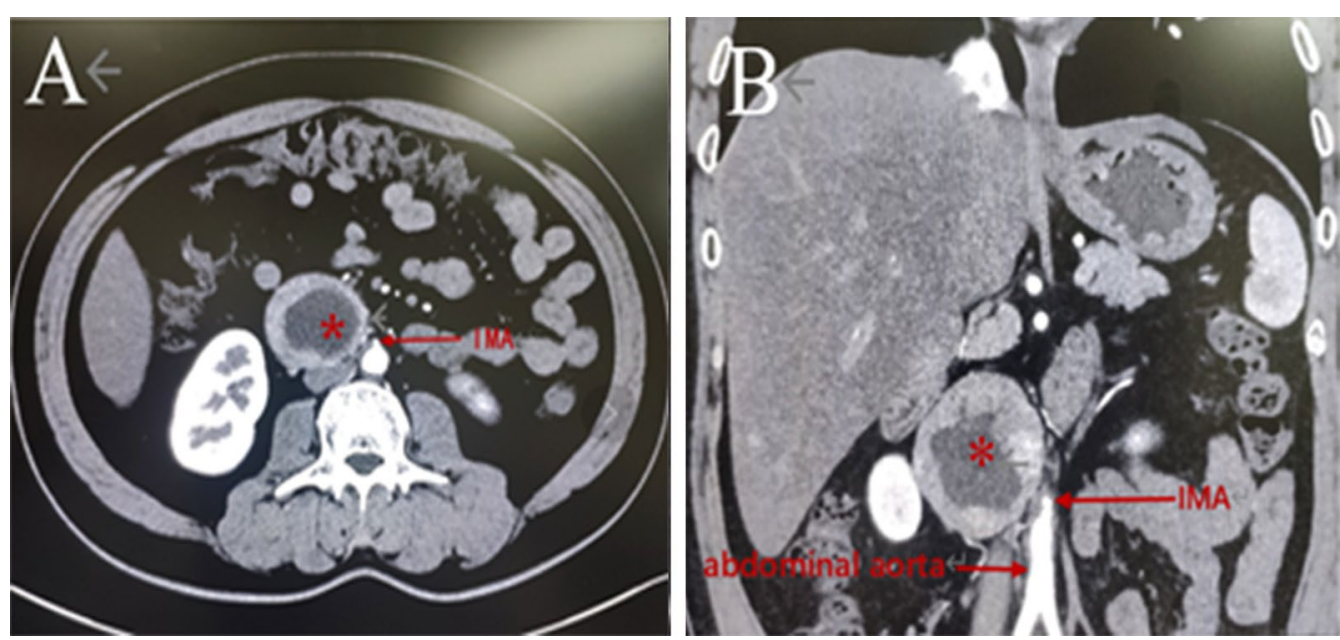

Fig. 1 CT findings: CT shows a $7.2 \times 6.5 \mathrm{~cm}$ right para-aortic mass (asterisk) located at the level of the inferior mesenteric artery (IMA). Transverse plane (a). Coronal plane (b) 
the patient's family economic reasons and the lack of MIBG scan examination equipment in our hospital, our patient did not undergo further MIBG scan examination. Then he was transferred to our center where attempts to preoperative preparation included expansion of intravascular volume and alpha blockade with phenoxybenzamine for 2 weeks even with the situation of normal blood pressure.

We made full consideration and preparation for possible conversion to open surgery before deciding to adopt laparoscopic surgery. If there were acute bleeding, small operation space, malignant tumor invasion or other parts of the injury that have to be converted to open surgery, we will use a longitudinal incision under the right costal margin for open surgery. In addition, we also communicated with vascular surgeons that if the aorta or the inferior vena cava were damaged, open resection and reconstruction of these vessels might be warranted.

The patient was placed in $70^{\circ}$ left lateral decubitus position, and a $10-\mathrm{mm}$ trocar was inserted above the umbilicus for telescope using. Another 10- $\mathrm{mm}, 10-\mathrm{mm}$ and 5 - $\mathrm{mm}$ trocar were placed under the right costal margin, right anterior axillary line and subxiphoid, respectively (Fig. 2). A steep Trendelenburg position allowed the small bowel and omentum to be moved away from the mass. First, cut the hepatic triangular ligament and hepatocolicum ligament with an ultrasonic shears, and lift the liver to expose the upper pole of the right kidney. The ascending mesocolon is then longitudinally incised and pushed open to expose the right kidney and the right renal vein, and the descending and horizontal parts of the duodenum are separated and pushed open, showing that the upper pole of the exposed tumor is filled with nourishing

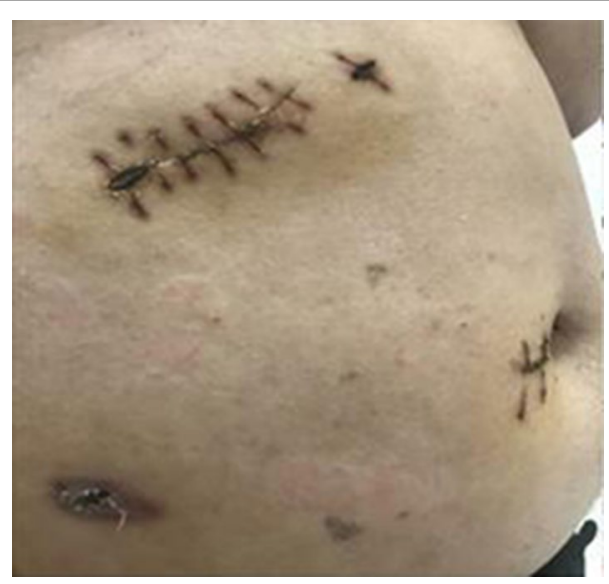

Fig. 2 Positions of the ports. A 10-mm trocar was inserted above the umbilicus, and another 10-mm, 10-mm and 5-mm trocar were placed under the right costal margin, right anterior axillary line and subxiphoid, respectively vessels. Then the vessels of nutritional tumors were separated and ligated one by one. Uncovering the lower part of the tumor, it can be seen that the inferior vena cava and abdominal aorta, and the abdominal aorta send out a thicker vascular supply tumor, which was ligated by Hemo-lock. The tumor and its surrounding tissues were then clipped along the tumor capsule and separated gradually. The well-encapsulated mass was excised. The mass was placed in a sample collection bag and removed through a 5-cm right upper abdomen incision that incorporated the incision made for the costal margin 10-mm port. Except for upon contact with the tumor blood pressure rose up to $160 \mathrm{mmHg}$ he remained stable throughout surgery. The total operative time was $120 \mathrm{~min}$ and intraoperative blood loss was around $50 \mathrm{~mL}$. The post-operative period was uneventful and he was discharged on post-operative day 5 . The histopathology found the tissue was consistent with a benign PGL and DNA analysis of SDHB and SDHD revealed no mutation. During 6 months follow-up after post-operative, urinary and serum catecholamines were within normal range but glycaemia remained high level (Table 2).

\section{Discussion and conclusion}

PGLs are rare catecholamine-secreting neuroendocrine tumors that arise from the extra-adrenal paraganglia. Most PGLs occur in the subdiaphragmatic region, most commonly within the organ of Zuckerkandl [8]. The clinical presentation of pheochromocytomas/PGLs can vary remarkably, from dramatic symptoms and signs to minimal or no symptoms whatsoever [9]. This latter situation is often termed "clinically silent" pheochromocytoma/ PGL $[10,11]$. Even though the patient with a clinically silent PGL experiences no symptoms and shows no signs of a PGL, blood and urine levels of catecholamines are often elevated [10-12]. This situation usually leads to misdiagnosis and missed diagnosis. Therefore, understanding its clinical characteristics is very important for the standardized diagnosis and treatment of clinical diseases. In our case, the patient without characteristic paroxysmal attacks of headache, sweating, palpitation and hypertension only presented with hyperglycemia. Although pheochromocytomas/PGLs can cause hyperglycemia and even induce diabetes type 2 [13], the patient's glycaemia remained high level at 6-month follow-up after post-operative when urinary and serum catecholamines were normal. It confirmed that this hyperglycemia was presumably not related to the POZ, but merely coincided by chance.

A giant PGL/pheochromocytoma usually present with paucity of clinical signs and symptoms $[14,15]$. The mechanism of clinically silent PGL/pheochromocytoma remains unclear. The reasons for the same can be due of 
the presence of tumoral necrosis, high loads of interstitial tissue compared to chromaffin cells or the paucity of the release of the catecholamines due to encapsulation by the connective tissues [15]. These cause normal catecholamine values during their serum and urinary assays [16]. There are also studies that believe that there is a self-metabolism mechanism of catecholamines inside the tumor, which prevents active catecholamines from being released into the blood [17]. These explanations are not consistent with our case. Therefore, the mechanism of this situation needs to be further explored in subsequent studies.

Previously, it was considered that there were no guidelines to ensure adequate preoperative preparation in these clinically silent tumors [10]. The present view holds that patients suspected of clinically silent pheochromocytoma should be given a high sodium diet and adequate fluid intake before surgery, and alpha blockade should be prepared for 7-14 days to avoid possible cardiovascular damage caused by abrupt blood pressure rise and fall and insufficient blood volume during and after surgery [18]. Surgical resection is the treatment of choice for POZ, and laparoscopic resection is suited for small $(<7 \mathrm{~cm})$ tumors [3]. Only eight cases of laparoscopic resection of POZ have been described till to 2020. Depending on their location, strategies utilized to approach the tumor included duodenal Kocherisation as well as colonic mobilization [3]. Under the situation of our patients with tumors $>7 \mathrm{~cm}$, we chose laparoscopic resection with duodenal Kocherisation, exposed the tumor directly after freeing the kidney, and early controlled the blood vessels from the abdominal aorta to reduce intraoperative bleeding and minimize intraoperative hemodynamic instability.

Most PGLs appear to be sporadic; however, about $30-35 \%$ of tumors are associated with hereditary syndromes, mainly multiple endocrine neoplasia type 2 (MEN-2), von Hippel Lindau (VHL) disease, and neurofibromatosis type 1 (NF1) [19]. 70\% of POZ cases are associated with SDHB or less commonly SDHD gene mutations [20]. In our case, blood calcitonin, serum free T3, free T4, and TSH levels were normal. These results make MEN-2 disease unlikely. Ophthalmological screening showed an absence of retinal hemangioblastoma that makes VHL disease unlikely. The lack of cutaneouscaféau-lait spots suggested the absence of NF1. DNA analysis of SDHB and SDHD revealed no mutation. In addition, genetic testing should be performed for at-risk family members [21].We once advised his family members to do the related genetic tests, but they refused due to the cost. Nonetheless, a predisposing genetic factor cannot be excluded since current research has revealed several other genes linked to familial and sporadic cases of pheochromocytoma [22]. Thus, we advised the patient to return for regular follow-up.

In conclusion, POZ is an unusual mass and preoperative diagnosis can be difficult in clinically silent cases. PGL cannot be excluded in patients with normal blood pressure. Even a large POZ can be excised laparoscopically by following proper techniques.

\begin{abstract}
Abbreviations
POZ: Paraganglioma of the Zuckerkandl organ; PGL: Paraganglioma; CT: Computed tomography; SDHB: Succinate dehydrogenase complex subunit B; SDHD: Succinate dehydrogenase complex subunit D; ECG: Electrocardiography; Max: Maximum; IMA: Inferior mesenteric artery; MEN-2: Multiple endocrine neoplasia type 2; VHL: Von Hippel Lindau; NF1: Neurofibromatosis type 1;TSH: Thyroid stimulating hormone.
\end{abstract}

\section{Acknowledgements}

Not applicable.

\section{Authors' contributions}

XR made contributions to the acquisition of history, image and wrote the manuscript. JS performed the treatment, and reviewed the manuscript to give clinical opinions. RR made supervision and helped reviewing the manuscript. $\mathrm{HZ}$ and $\mathrm{XY}$ reviewed the manuscript and were involved in its critical revision before submission. All authors read and approved the final manuscript.

\section{Funding}

This study was supported by Shanxi Province Science and Technology Fund (Award No. 201903D321130). They provided financial support for the manuscript revising and data collecting.

\section{Availability of data and materials}

All data supporting our findings are contained within the manuscript.

\section{Ethics approval and consent to participate}

Not applicable.

\section{Consent for publication}

Written informed consent was obtained from the patients for publication of this Case Report and any accompanying images. A copy of the written consent is available for review by the Editor of this journal.

\section{Competing interests}

The authors declare that they have no competing interests.

\section{Author details \\ ${ }^{1}$ Graduate School, Shanxi Medical University, Taiyuan 030000, China. \\ 2 Department of Urology, Shanxi Bethune Hospital, No. 99 Longcheng Street, Taiyuan 030032, Shanxi, China.}

Received: 21 August 2020 Accepted: 29 September 2020

Published online: 07 October 2020

\footnotetext{
References

1. Ilias I, Pacak K. A clinical overview of pheochromocytomas/paragangliomas and carcinoid tumors. Nucl Med Biol. 2008;35(Suppl 1):S27-34.

2. Sarveswaran V, Kumar S, Kumar A, Vamseedharan M. A giant cysticpheochromocytoma mimicking liver abscess an unusual presentation-a case report. Clin Case Rep. 2015;3(1):64-8.

3. Salgaonkar H, Behera RR, Sharma PC, Chadha M, Katara AN, Bhandarkar DS. Laparoscopic resection of a large paraganglioma arising in the organ of Zuckerkandl: report of a case and review of the literature. J Minim Access Surg. 2016;12(4):378-81.
} 
4. Kravarusic D, Pinto-Rojas A, Al-Assiri A, Sigalet D. Laparoscopic resection of extra-adrenal pheochromocytoma - case report and review of the literature in pediatric patients. J Pediatr Surg. 2007;42(10):1780-4.

5. Thapar PM, Dalvi AN, Kamble RS, Vijaykumar V, Shah NS, Menon PS. Laparoscopic transmesocolic excision of paraganglioma in the organ of Zuckerkandl. J Laparoendosc Adv Surg Tech A. 2006;16(6):620-2.

6. Cozzupoli P, Veneziano D, Sicuro O, Carbone L, Sgrò E. Laparoscopic resection of a large functional paraganglioma in the organ of Zuckerkandl. Urology. 2011;71:S168

7. Joshi CJ, Bhat S. 2018 Organ of Zuckerkandl: laparoscopic excision of a rarity. Indian J Surg. 2018;9486:1

8. Gill T, Adler K, Schrader A, Desai K, Wermers J, Beteselassie N. Extra-adrenal pheochromocytoma at the organ of Zuckerkandl: a case report and literature review. Radiol Case Rep. 2017;12(2):343-7.

9. Hodin R, Lubitz C, Phitayakorn R, Stephen A. Diagnosis and management of pheochromocytoma. Curr Prob Surg. 2014;51(4):151-87.

10. Shen SJ, Cheng HM, Chiu AW, Chou CW, Chen JY. Perioperative hypertensive crisis in clinically silent pheochromocytomas: report of four cases. Chang Gung Med J. 2005;28(1):44-50.

11. Kota SK, Kota SK, Panda S, Modi KD. Pheochromocytoma: an uncommon presentation of an asymptomatic and biochemically silent adrenal incidentaloma. Malays J Med Sci. 2012;19(2):86-91.

12. Yoshida K, Sasaguri M, Kinoshita A, Ideishi M, Ikeda M, Arakawa K. A case of a clinically "silent" pheochromocytoma. Pheochromocytoma. Jpn J Med. 1990;29(1):27-31.

13. Havekes B, Pacak K. Pheochromocytoma. Nat Clin Pract Cardiovasc Med. 2008;5:E1.

14. Munakomi S, Rajbanshi S, Adhikary PS. Case report: a giant but silent adrenal pheochromocytoma - a rare entity. F1000Res . 2016:5:290.

15. Li C, Chen Y, Wang W, Teng L. A case of clinically silent giant right pheochromocytoma and review of literature. Can Urol Assoc J. 2012;6(6):E267-9
16. Wang HL, Sun BZ, Xu ZJ, Lei WF, Wang XS. Undiagnosed giant cystic pheochromocytoma: a case report. Oncol Lett. 2015;10(3):1444-6.

17. Peyrin L, Cottet-Emard JM, Cottet-Emard RM, Vouillarmet A. The diagnosis of atypical pheochromocytoma: a challenge for the biologist as well. Pathol Biol (Paris). 2001:49(3):247-54.

18. Zhu GD, Tang C, Song WB, Yang ZS, Zhang Y, Fan JH, et al. Surgical treatment of 137 cases of pheochromocytoma/paraganglioma: outcome analysis and clinical experience from a single institution. J Mod Urol. 2017;08:36-40.

19. Costa MH, Ortiga-Carvalho TM, Violante AD, Vaisman M. Pheochromocytomas and paragangliomas: clinical and genetic approaches. Front Endocrinol (Lausanne). 2015:6:126.

20. Lodish MB, Adams KT, Huynh TT, Prodanov T, Ling A, Chen C, Shusterman S, Jimenez C, Merino M, Hughes M, et al. Succinate dehydrogenase gene mutations are strongly associated with paraganglioma of the organ of Zuckerkandl. Endocr Relat Cancer. 2010;17(3):581-8.

21. Chen H, Sippel R, O'dorisio S, Vinik A, Lloyd R, Pacak K. Pheochromocytoma, paraganglioma, and medullary thyroid cancer. The North American Neuroendocrine Tumor Society Consensus Guideline for the diagnosis and management of neuroendocrine tumors. Pancreas. 2010;39(6):775-83.

22. Shuch B, Ricketts CJ, Metwalli AR, Pacak K, Linehan WM. The genetic basis of pheochromocytoma and paraganglioma: implications for management. Urology. 2014;83(6):1225-32.

\section{Publisher's Note}

Springer Nature remains neutral with regard to jurisdictional claims in published maps and institutional affiliations.
Ready to submit your research? Choose BMC and benefit from:

- fast, convenient online submission

- thorough peer review by experienced researchers in your field

- rapid publication on acceptance

- support for research data, including large and complex data types

- gold Open Access which fosters wider collaboration and increased citations

- maximum visibility for your research: over $100 \mathrm{M}$ website views per year

At $\mathrm{BMC}$, research is always in progress.

Learn more biomedcentral.com/submissions 